\title{
Antropología interactiva: consciencia y práctica dual del rol del antropólogo en una sociedad multiétnica y multicultural ${ }^{1}$
}

\author{
Teresa Durán y Marcelo Berho ${ }^{2}$
}

\begin{abstract}
Resumen
El texto explora en las posibilidades de construir conocimiento profesional y disciplinario de carácter antropológico en un contexto multiétnico y multicultural. Para ello, se establecen relaciones entre el conocimiento antropológico y el social sobre tópicos de interés antropológico, fundando esta posibilidad en un análisis - teórico de las prácticas que permita re-orientar las mismas en un contexto de enseñanza de la antropología. En el marco de este análisis, el artículo otorga importancia a los procesos que viven las sociedades, particularmente las latinoamericanas, y al papel de los enfoques de antropología que se han distinguido desde los inicios de la disciplina. A raíz de estos análisis, los autores proponen y fundamentan la posibilidad de una antropología aplicada contemporánea (antropología interactiva) que, sin dejar de discernir su praxis en el marco de la sociedad y de la cultura local, es capaz de trascenderla a través de una visión explicativa y prospectiva, tanto de los procesos sociales como de esta misma praxis.
\end{abstract}

\begin{abstract}
This text explores the possibilities of constructing professional and disciplinary athropological knowledge in a multicultural context. To this end, the authors seek to establish relations between anthropological knowledge and its socia milieu, founded in the possibility of a meta-theorisation of anthropological practices that permits a reorientation of these sames practices within the context of the teaching of anthropology. Within this analytical framework, the article focusses on those proceses which animate societies, and in particular Latin American societies, as well as on the role of the more traditional areas of emphasis which have characterized the practice of anthropology from its inception. In response to such reflections, the authors propose, and situate themselves within, the possibility of a contemporary applied anthropology
\end{abstract}

(interactive anthropology) that, without forgoing its engagement with the local society and culture in which it finds itself, is capable of transcending praxis, through an explanatory and prospective vision of both broader social processes and praxis itself.

\section{Introducción}

$\mathrm{P}$ ara una de las corrientes epistemológicas contemporá neas, la de los constructivistas radicales, "es imposible un conocimiento seguro del mundo...". Esta es una afirmación detonante en relación a la influencia que ha logrado tener el modelo clásico de ciencia. Estos pensadores proponen que mediante "la asociación", es decir, la capacidad de "encadenar objetos ya integrados, a través de la representación de ordenaciones espaciales o secuencias temporales y vinculando una experiencia con otra, es posible que podamos construir conocimiento". Glasersfeld plantea la posibilidad de construir "estructuras, en tanto productos de nuestra propia y característica capacidad de representación" (Glasersfeld, 1998: 19-23).

Supuestos teóricos y epistemológicos de este orden sustentan no sólo el paradigma que permite la construcción del conocimiento antropológico sino particularmente del quehacer que denominamos "antropología aplicada". Esta posibilidad, por tanto, es controversial y no constituye un quehacer ciego o rutinario.

Si la antropología aplicada ha llegado a ser dudosa en su orientación ética y política, desde luego que la controversia es aún más profunda si nos movemos en el marco de estos supuestos, dado que ellos interpelan al concepto mismo de ciencia. Hemos detectado que cuando la antropología aplicada se sustenta en el modelo de ciencia clásica, posibilita el conocimiento descansando su validez sobre fundamentos metodológicos y, desde esta perspectiva, el "esfuerzo científico" del antropólogo estará puesto en el plan de trabajo.

1 Este trabajo constituyó una ponencia originaimente presentada en el Congreso Mundial de Antropología y Ciencias Etnológicas, Florencia, 2003.

2 Ambos son Investigadores y docentes miembros del Centro de Estudios Socioculturales (CES) y la Escuela de Antropologia de la Universidad Católica de Temuco (UCT), Chile. Aunque los autores asumen la responsabilidad directa del presente articulo, otros miembros del equipo han hecho destacadas contribuciones a la base de datos. Nuestros agradecimientos, en este sentido, a Noelia Carrasco, Héctor Mora, Alvaro Ugueño, Loreto Eyzaguirre, Verónica Nuñez y Lina Gutiérrez. 
Por medio de continuas reflexiones pareciera ser que nos estamos liberando de esta concepción, lo que supone que el mayor esfuerzo debe descansar en el ordenamiento del quehacer de parte del propio antropólogo, sin que ello no involucre necesariamente a los sujetos. El adoptar una intencionalidad como esta nos acerca a epistemólogos como Maturana (1998) que asocian la lógica del trabajo científico con la lógica de la vida cotidiana. Este autor, por ejemplo, destaca el papel de los ámbitos experienciales, los que, en tanto tales, pueden también constituir y consolidar "la experiencia de explicar... si se tiene la pasión de explicar". En este sentido, la ciencia, como experiencia y más allá del objeto, aparece posible, no đependiendo del método, sino del sujeto que tiene la "pasión por explicar".

En nuestra experiencia de buscar explicaciones a preguntas tales como:

1) ¿cuáles son las posibilidades de construir conocimiento profesional y disciplinario de carácter antropológico en un contexto multicultural?;

2) ¿de qué modo se relaciona el conocimiento antropológico con el conocimiento social sobre tópicos de interés antropológico? y

3) ¿qué posibilidades existen para que el análisis de las prácticas re-oriente las mismas en un contexto de enseñanza de la antropología?

hemos encontrado explicaciones que se sitúan, por un lado, en el poder de los métodos $\mathrm{y}$, por otro, explicaciones que descansan mayormente en la reflexividad del sujeto que plantea las preguntas; del mismo modo como, en la forma, le podría ocurrir a los propios sujetos sociales no involucrados en tareas de una especialidad como la antropología. En tal experiencia, no obstante, siempre el fenómeno explicativo y el explicado constituirá un ámbito relacional abstracto de naturaleza diferente del que le dio origen. Lo que equivale a decir que las explicaciones encontradas son de responsabilidad del buscador de explicaciones, si bien al ponerse a prueba pueden derivar también en propuestas explicativas para otros. En este sentido, puede decirse que las explicaciones que buscamos debieran someterse a un patrón que las validará en tanto construcciones, mientras que ésta no será una premisa necesaria para los actores sociales involucrados. Así, si bien las especialidades de las ciencias sociales -y entre ellas, la antropología- han puesto en duda o han sido escépticas respecto de que se pueda contar con explicaciones determinísticas que permitan, a su vez, controlar el plan de acción, no por ello se desconocerá que este tipo de explicación $y$, por tanto, de enfoque científico, sea posible de encontrar en la experiencia.

De este modo, la antropología aplicada contemporánea (AAC) puede caracterizarse como tal en base a los siguientes rasgos: a) si descansa en el interés y voluntad del sujeto por buscar explicaciones a los eventos en los que se ve involucrado;

b) si asume que tales explicaciones deberán ser específicas o particulares en tanto "procesos explicativos" que involucran a los actores sociales;

c) si asume que es posible enlazar tales tipos de explicaciones particulares buscando una forma explicativa más global; y

d) si incluye en estas cadenas explicativas su propia influencia "a través de reflexiones recursivas acerca de nuestra circunstancia" (Maturana, 1998: 198).

Lo anterior quiere decir que creemos posible el quehacer científico en el ámbito de la antropología aplicada, en tanto se asume ésta como una prolongación de la antropología general, pero en el marco de un enfoque en el que el especialista se dispone a buscar explicaciones con la intención de comprender "nuestras circunstancias" y "mejor actuar" en los ámbitos en que la acción social se expresa en contextos dados.

En esta oportunidad deseamos comunicar un avance más hacia la formalización a nivel local respecto del análisis meta-teórico (Ritzer, 1996) a que hemos estado sometiendo nuestras prácticas profesionales (PP) y disciplinarias (PD) en el marco de lo que entenderemos como AAC. Entendemos por análisis metateórico a la sistematización, en este caso de las prácticas, como objetos de estudio y, por tanto, como fuentes de datos relevantes respecto de preguntas de investigación.

La metodología empleada ha sido de orientación etnográfica en la perspectiva reflexiva (Hammersley y Atkinson, 1994), aplicada a prácticas situadas en contextos formales de interacción profesional y disciplinaria en los últimos cinco años. Esta data ya había sido analizada anteriormente con intereses similares: primeramente, con fines de postular la posibilidad particular de una antropología aplicada que, situándose en temáticas de carácter antropológico, tales como la marginalidad social y las relaciones interétnicas, otorgara importancia al manejo del rol disciplinario por parte del antropólogo. ${ }^{3}$

En esta misma línea, se había advertido la necesidad de diferenciar y articular roles dependiendo de la naturaleza del corpus sociocultural involucrado (Samaniego y Durán, 2003). Un esfuerzo decidido hacia la problematización del crecimiento del corpus científico a partir de la antinomia entre la antropología y la sociedad fue presentado en las III Jornadas de Antropología de la Escuela de Antropología de la UCT. En aquella oportunidad postulamos que era posible producir un avance analítico respecto del quehacer disciplinario y profesional diferenciado, transitando desde el plano monológico intra-disciplinario a un

3 Se trata del texto "Antropología aplicada interactiva: una propuesta desde La Araucanía, Chile", presentado en la Conferencia de Antropologia Aplicada, México, febrero de 2000. 
plano multifocal nutrido desde las propias prácticas disciplinarias, en tanto acciones participantes de la realidad social. ${ }^{4}$

En esta oportunidad deseamos focalizar, a partir de las tres preguntas anteriormente planteadas, el concepto del rol dual de la antropología a modo de prueba de que, en carácter de variable analítica, este concepto juega un papel cognoscitivo de relevancia en la construcción de conocimiento, sea éste de carácter social o de orden antropológico.

El plan de análisis consiste en situar el contexto de las PP y PD respecto de "ámbitos" o variables de trabajo ("variables complejas" (VC)); y, luego, llevar a cabo un análisis descriptivo de la data considerando antecedentes etnográficos pertinentes al ámbito considerado.

Se seleccionaron tres ámbitos o conjunto de variable complejas (VC):

1) las conceptualizaciones de antropología,

2) la vinculación entre sociedad y antropología mediando una demanda explícita, y

3) la enseñanza de la antropología.

En cuanto al contexto, éste se diferenciará, para fines analíti$\cos$, en contexto social mayor (CSM) y contexto social antropológico (CSA). En cuanto al CSM, nuestra principal fuente de experiencia vital transcurre en un contexto multiétnico y multicultural como es la región de La Araucanía, en el centrosur de Chile. Esta es una región de frontera étnico - cultural que se conforma jurídicamente en la segunda mitad del siglo XIX, en la que se instala el modelo de estado - nación. Este modelo conlleva o trae consigo la implementación de las diversas formas de colonización conocidas en Latinoamérica en lo que se refiere a la distribución de los territorios y el establecimiento de un sistema político republicano que hoy día se expresa en una constitución mono-cultural basada en el derecho positivo. En este sentido, el modelo del estado - nación ejerce la soberaníano sólo sobre los territorios sino sobre las poblaciones humanas pre-existentes y prevalentes en ellos, específicamente respecto de la sociedad y cultura mapuche (Vidal, 1999).

En cuanto al CSA, éste ha permitido analizar la experiencia en relación con algunos hitos históricos específicos relacionados entre sí:

a) El primero abordó el tema de la enseñanza institucionalizada en relación a ciertos modelos de antropología (1998 - 2002), específicamente, en los que confluyen modelos originarios, transplantados y reproducidos en el contexto local. Estos análisis han continuado hasta el presente y de ellos deriva la primera de las problemáticas (Durán, 2002). b) Otro ángulo de análisis estuvo centrado en la institucionalización de una PP y antropológica caracterizada por alternar el rol disciplinario y profesional en la sociedad, la que dio lugar a la propuesta de la antropología interactiva (CES - UCT, 2000).

c) La experiencia actual incluye, además, un análisis sobre acercamientos antropológicos específicos a temáticas sociales recurrentes en la antropología local, tales como relaciones interétnicas e interculturales, marginalidad social, salud y medio ambiente, metodologías para contextos multiétnicos y multiculturales, etc. (1997-2003).

El carácter común de esta experiencia es que ha estado ligada a la práctica disciplinaria y a la formación de profesionales en antropología, transformándose en un grupo de trabajo activo con responsabilidades profesionales y de formación de nuevas generaciones, en contacto con generaciones de antropólogos de otras latitudes, latinoamericanos y europeos (CES y Escuela de Antropología). En el marco de las realidades administrativas como las señaladas, se ha generado investigación interdisciplinaria y aplicada, abierta al concurso de diversos especialistas interesados.

Al vincular las prácticas aludidas (PP y PD) con corpus teóricos vigentes en la disciplina, debemos situarnos en tendencias que parten con posterioridad y/o simultáneamente al surgimiento de la concepción de ciencia como sistema sociocultural (Kuhn, 1971). En esta línea de análisis, el trabajo de Bourdieu (2000) ha sido muy esclarecedor. En forma más específica, la caracterización y análisis de la experiencia -data- se apoya en la bibliografía disponible acerca de los aportes que antropólogos europeos y latinoamericanos han hecho respecto de temáticas tales como teoría y práctica de la antropología (Azcona, 1999; Ulin, 1990; Luque, 1999); autores que, desde una revisión crítica del quehacer antropológico, reflexionan acerca de los desafíos que la contingencia latinoamericana plantea al rol de la antropología (Marzal, 1994); autores que, desde un contexto latinoamericano, se plantean interrogantes acerca del destino de las poblaciones latinoamericanas respecto de las europeooccidentales (García Canclini, 2002). En este mismo plano, se recogen también los aportes de filósofos sociales que reflexionan acerca del papel de la ciencia en la conformación de las bases culturales de la sociedad y del quehacer cognoscitivo (Morin, 1998; Spire, 2000). En este mismo sentido, reconocemos la validez de los planteamientos de antropólogos teóricos interpretativos de corriente posmoderna (Geertz, 2000; Taussig, 1995). Un papel destacado en estas reflexiones se le otorga a aquellos especialistas que, trascendiendo el marco de sus respectivas disciplinas, hacen emerger planteamientos trans-disciplinarios para abordar el tema de la pobreza o la relación entre ética y desarrollo (Funtowicz y Ravetz, 2000), así como sociólogos que, en una postura similar, actualizan las teorías clásicas

4 En particular el trabajo "Antropología y sociedao", expuesto con ocasión de las III Jornadas de Antropología de la Escuela de Antropologia de la Universidad Católica de Temuco, Chile, en noviembre de 2002 . 
para hacer emerger imágenes interpretativas de la sociedad como sistema en permanente proceso de estructuración (Giddens, 2000).

Así, el análisis se nutre de aportes que abordan problemáticas tales como las relaciones entre el comportamiento individual y la estructura social (Stuchlik, 1976, Giddens, 1997), la diferenciación de niveles de realidad en el comportamiento sociocultural (Holy y Stuchlik, 1987; Holy y Stuchlik, 1988), problemas de integración - exclusión y nuevos modelos de integración (Cabrera, 1998; Romaní, 1998; Kliksberg, 2000), relación entre lógicas de pensamiento distinto (Durán, 2000), relaciones conocimiento - práctica (Azcona, op. cit.), entre otras fuentes.

Lo anterior debe entenderse estrictamente en el sentido en que estas problemáticas están a la base de nuestra preocupación y no son materia de la misma. Sí es materia de nuestra preocupación el estudio etnográfico - antropológico que se ha hecho de los tres ámbitos arriba señalados como producto de una experiencia profesional y disciplinaria en un contexto dado. Esto quiere decir que el contenido del presente texto está referido a la tematización de unas problemáticas antropológicas derivadas de una experiencia reflexionada de orden etnográfico antropológico; experiencia que proyectaremos en la búsqueda de indicadores sintomáticos que posibilitan y dificultan el ejercicio del rol dual en nuestro contexto que, según sospechamos, es más o menos similar al de otros contextos latinoamericanos, de modo de poder visualizar la transversalidad del rol antropológico en la sociedad local tras la búsqueda de una visión analítica de mayor alcance.

\section{Análisis meta-teórico.}

\section{Polivalencia del concepto de antropología}

Un tema recurrente en el quehacer antropológico es el de su conceptualización. Particularmente hemos observado que, desde el CSM latinoamericano, esta recurrencia emerge con gran profusidad, aludiendo a la versatilidad del contenido. En el contexto académico, en tanto, esta conceptualización es inherente a la práctica misma, sea para operacionalizar los conceptos o para redefinirlos actualizándolos, por lo que no constituye una práctica problemática. No obstante, los especialistas se refieren al hecho, a veces, metafóricamente. Para referirse al tema, Geertz (Op. cit.) sostiene que "no se sabe lo que es la antropología", ".... nadie sabe a ciencia cierta qué es la antropología". Esto querría decir que no existiría un parámetro fijo e inflexible que evalúe los desempeños. No obstante, este mismo autor y otros, señalan que la historia de la antropología es dramática si se consideran sus recorridos tormentosos entre los paradigmas científico - sociales, cuestión que nosotros comprobamos en la literatura (Harris, 1990; Reynoso, 1998; Luque, op. cit.; Geertz, 1996; Ulin, op. cit.). Desde luego, hay autores que, como el mismo Geertz, no dudan en recurrir a definiciones esencialistas tales como: la antropología "es la disciplina que se dedica a la totalidad de la vida y del pensamiento humano", "es la disciplina que ha hecho de la variedad del mundo la base directa de su pensamiento... que ha desentrañado las singularidades de los modos de vida de otros pueblos...", etc. (op. cit.: 1 - 15), a través de las cuales zanjan la cuestión; conceptualizaciones ideográficas en este sentido son menos recurrentes, por lo que no es fácil contar con un cuadro que sitúe el origen y sentido de las distintas conceptualizaciones y el papel que cumplen en el desempeño del rol.

En una perspectiva social, esta circunstancialidad puede ser ventajosa en un sentido diferente al referido anteriormente, es decir, puede constituir una fuente de problematizaciones necesarias para orientar el quehacer.

Tomando en cuenta nuestra experiencia, afirmamos que cuando la antropología se vincula a escenarios sociales diversos, quizás en mayor grado que otras disciplinas de las ciencias sociales, ésta es objeto de conceptualizaciones múltiples no sistemáticas, siendo necesario establecer sus límites, relaciones e impactos. Ello se asocia a una imagen difusa que, aparentemente, conforma un ambiente de incertidumbre y desasosiego a la hora de llevar a cabo la PP, pero, al mismo tiempo, esta circunstancia puede dar origen a una visión de imágenes simbolizadas de la antropología en la sociedad, al mismo tiempo que a dificultades relevantes de cómo interactuar con ella a través de sus instituciones.

En el cuadro siguiente se grafica una visión analítica compleja respecto de la polivalencia del concepto de antropología según contextos sociales, institucionales y fases históricas cruzados por las variables propias del quehacer, tales como objeto, métodos, teorías y utilidades. 
Cuadro 1. Polivalencia del concepto de antropología

\begin{tabular}{|c|c|c|c|}
\hline Objeto & $\begin{array}{l}\text { - Estudio del hombre y de su evolución } \\
\text { - Estudio de culturas particulares } \\
\text { - Estudio de las sociedades y culturas del } \\
\text { mundo } \\
\text { - Estudio del comportamiento individual y su } \\
\text { relación con las estructuras sociales y la cul- } \\
\text { tura }\end{array}$ & $\begin{array}{l}\text { - Estudio del hombre } \\
\text { - Estudio de "costumbres extrañas, } \\
\text { cacharros y cráneos"s } \\
\text { - Estudio de los restos arqueológicos } \\
\text { y de las culturas antiguas o del pasado } \\
\text { - Estudio de culturas indígenas }\end{array}$ & $\begin{array}{l}\text { - Estudio del hombre } \\
\text { - Estudio de los restos arqueológicos } \\
\text { o del pasado } \\
\text { - Estudio de culturas indígenas y/o exó- } \\
\text { ticas }\end{array}$ \\
\hline Métodos & $\begin{array}{l}\text { - Trabajo de campo } \\
\text { - Etnografía } \\
\text { - Comparación }\end{array}$ & $\begin{array}{l}\text { - Viajes exóticos } \\
\text { - Convivencia con nativos }\end{array}$ & $\begin{array}{l}\text { - Descubrimiento y conservación de cul- } \\
\text { turas exóticas } \\
\text { - Estudios de impacto } \\
\text { - Estudios de evaluación de políticas so- } \\
\text { ciales } \\
\text { - Investigación sociocultural } \\
\text { - Adecuación de metodologías de pla- } \\
\text { nificación }\end{array}$ \\
\hline Teorías & $\begin{array}{l}\text { - Perspectiva comparativa transcultural } \\
\text { - Estudio etic que explica el origen y desa- } \\
\text { rrollo de los fenómenos socioculturales, par- } \\
\text { ticularmente los de orden estructural } \\
\text { - Estudio del comportamiento individual y } \\
\text { su relación con las estructuras sociales y la } \\
\text { cultura } \\
\text { - Teorías de la acción }\end{array}$ & $\begin{array}{l}\text { - Estudio de la evolución humana } \\
\text { - Estudio y promoción del cambio so- } \\
\text { cial }\end{array}$ & $\begin{array}{l}\text { - Estudio de universales de la cultura: } \\
\text { salud, educación, derecho, desarrollo, } \\
\text { organización social, lengua }\end{array}$ \\
\hline Controversias & $\begin{array}{l}\text { - Antropología como ciencia colonialista } \\
\text { - Antropología como estudio humanístico a- } \\
\text { científico }\end{array}$ & $\begin{array}{l}\text { - Baja acreditación científica por asumir } \\
\text { diversidad sociocultural } \\
\text { - Científico social crítico de la sociedad, } \\
\text { de sus sistemas y actores sociales } \\
\text { - Fundamento de sistemas etnocéntricos } \\
\text { y xenofóbicos }\end{array}$ & $\begin{array}{l}\text { - Tensión entre modemización y tradición } \\
\text { - Tensión entre cambio político y } \\
\text { cultural }\end{array}$ \\
\hline
\end{tabular}


El cuadro representa una trama en la cual se demuestra que las conceptualizaciones de antropología no son caóticas -aun cuando sean variadas-, pues son susceptibles de ser ordenadas según variables concurrentes. La variabilidad depende de los contextos, pero está sujeta a variables unívocas que hoy día son distinguibles entre sí. Esta matriz sólo sería negada en contextos donde no se ha divulgado la noción, como en sectores rurales y/o sub-urbanos. Ambas circunstancias tienen un impacto de diferente tipo en el ejercicio dual del rol. En términos generales, el rol profesional se ve obligado a confrontarse de modo directo con la polivalencia susceptible de ser encontrada en el contexto de que se trate, afectando de forma directa la relación humana que el antropólogo sostenga, así como sus desempeños. El rol disciplinario, en cambio, puede desempeñarse de manera independiente a esta polivalencia, aunque incide de manera gravitante en el desempeño de la PP y, especialmente, a nivel de la controversia, inclinando la balanza hacia una visión positiva de la antropología y/o negativa y perturbadora. De aquí se deriva una recomendación formativa respecto de la necesidad de tener que esclarecer la forma y contenido de las nociones sobre la disciplina que convergen en un contexto dado al iniciar la PP para evaluar el impacto que las prácticas mismas puedan tener en el movimiento o dinámica de estas nociones. En esta perspectiva, y como lo han expuesto otros especialistas (Rosaldo, 1999), el desempeño individual resulta ser relevante, así como la condición sociocultural del antropólogo, su género, edad, etnicidad, experticia, etc.

En síntesis, podemos decir que particularmente en contextos donde la divulgación del rol ha tenido lugar, persisten nociones recurrentes de la antropología más allá de su validez disciplinaria que se usan para derivar de ellas criterios evaluativos del rol, determinando así niveles de acceso y de legitimación de las prácticas $y / 0$ desempeños.

A continuación se señalan ejemplos resumidos de situaciones en las cuales la VC-polivalencia conceptual- juega un papel importante en las PP y las PD.

En contextos académicos se asume que pueden darse distintas formas de ejercer la disciplina, siendo criterios relevantes el manejo de los métodos, las teorías y las especialidades, las que influirán en la conformación de equipos interdisciplinarios y en las respectivas PP y PD observables en la elaboración de distintas tareas, tales como proyectos especializados, tareas administrativas, etc. En este contexto académico, la variable interviniente descansa más bien en la ética profesional que en el desempeño disciplinario mismo, aun cuando este último es también significativo, dado que la experiencia demuestra que la asunción de modelos teóricos tiene consecuencias sociales. La explicitación de la perspectiva dual en antropología médica, en tanto modelo teórico que privilegia la atención en la "práctica clínica" (Young, 1990), ha operado en la región en la medida en que antropólogos locales han propuesto la institución del facilitador cultural, propuesta institucionalizada vigente que ha sido altamente controversial respecto de la necesidad de instalar perspectivas más amplias para orientar la "práctica clínica" en contextos interétnicos e interculturales. Otro ejemplo puede derivarse de circunstancias en que una institución internacional solicita una investigación antropológica que, en el marco de las corrientes posmodernas, requieren la actualización de percepciones de los distintos actores respecto de una variable dada, desconociendo al mismo tiempo la importancia de considerar apropiadamente la relación histórica, estructural y sociocultural de variables étnico - culturales. En casos como éste, la modernización de la antropología va en contra del proceso de acumulación teórica que la disciplina necesariamente requiere en algunos contextos, particularmente en el multiétnico en el que nos desenvolvemos. ${ }^{6}$

En contextos institucionalizados no académicos, dependiendo de la influencia de la variable "controversia" puede darse la exclusión del desempeño del rol si éste no concurre con certeza al tipo de utilidad que está establecido al interior del contexto. Si esto ocurre así es probable que la PD se vea disminuida, por lo que la dualidad del rol se vería clausurada. Esta clausura puede también derivarse directamente del sujeto antropólogo: al depender de su voluntad o imposibilidad de actuar el rol disciplinario por razones formativas, ello impactará de modo diverso en la satisfacción de la noción simbólica o ideacional del rol que prevalece a nivel institucional no académico. Otro ejemplo, en este contexto, permite advertir que, por la carencia de asociación entre la noción convencional de antropología y temáticas de marginalidad urbana contemporáneas, se prioriza la noción disciplinaria desempeñada, asumiendo que el rol profesional no tiene cabida o sentido futuro en el marco de las estructuras político-contingentes que imperan en la sociedad; en otras palabras, se redefine el rol mayormente en los términos disciplinarios relegando la dimensión profesional a un "acompañamiento sensible".

En términos prospectivos, hemos advertido que el cuadro anterior ha tenido un enorme impacto para efectos de la interacción del rol, particularmente en la dimensión profesional, permitiéndosenos afirmar que la delimitación de la noción delimita a su vez la interacción y, al mismo tiempo, la posibilidad de la actualización del rol disciplinario en la sociedad. Ello pondrá al antropólogo en el desafío de intentar eludir o cambiar la noción dependiendo del sujeto con el que le corresponda trabajar. Por ejemplo, con respecto a la noción de que el antropólogo es el estudioso por antonomasia de los pueblos indígenas, puede ocurrir que éste, como es nuestro caso, mantenga en latencia y actúe esa noción si los cuadros empíricos que la sostienen son constitutivos del poder local contingente, o intente cambiarla si se trata de sectores indígenas con los que ha sostenido una interacción previa que ha permitido redefinir la noción convencional, esto es, ir desde la relación informante -investigador a la de co-investigador de la relación. Lo anterior supone reconocer que, en este campo, el mayor cultivo de la antropología será en el ámbito disciplinario más que en el profesional. Al

6 Este caso, en el cual se desempeñó un rol disciplinario por excelencia, provino de un tipo de investigación intemacional en el campo de las migraciones. 
revés, por parte de otros sectores de antropólogos, se ha observado que el rol profesional se ha exacerbado al interior de las instituciones públicas y privadas con desmedro casi absoluto del cultivo del rol disciplinario.

La similitud entre los contextos académicos y no académicos sería el ejercicio del rol disciplinario, mediado por la práctica ética, aunque con impactos diferentes.

A nivel de las reflexiones que se han dado en la Escuela de Antropología regional, hoy día es posible distinguir tres tipos de desempeños que comprometen la condición ética del quehacer. El primer tipo concierne a la ética propia de la disciplina; luego tenemos el relativo al ámbito de los desempeños socioprofesionales y, por último, aquel que concierne al ámbito del sujeto como ser social.

En el plano de la sociedad, este último ámbito es o no el más determinante, siendo una de las tendencias el que no lo sea porque la sociedad no puede incursionar en la privacidad de la vida de las personas ni usar criterios moralistas para evaluar desempeños profesionales y/o disciplinarios. Nuestra postura es que la influencia de uno u otro ámbito de la ética está asociado al tipo de sociedad y nivel cultural que tal sociedad detente en un tiempo y espacio determinados.

El análisis de las experiencias revela que el ámbito de la polivalencia conceptual es inherente a la dinámica social, dado que es reproducida por el quehacer o acción tanto por parte de antropólogos como de no antropólogos. En otras palabras, esta variable es insoslayable respecto de la dualidad del rol, en tanto constituye una determinante sociocultural y/o institucional y, al mismo tiempo, es soslayable y/o manipulable dependiendo del comportamiento social de unos y otros, siendo posible al mismo tiempo analizarlas desde esquemas estructurales y procesales (Rosaldo, op. cit..).

Lo anterior concuerda con la afirmación teórica que los especialistas contemporáneos transaccionalistas (Holy y Stuchlik, Op. cit.) han sostenido acerca de que el comportamiento sociocultural es genéricamente similar entre los individuos y que, al conformar nichos culturales, se permite una visón explicativa de las relaciones socioculturales que se establecen entre ellos. La AAC que estamos proponiendo se sustenta en estos supuestos teóricos, pero incluye los desempeños de las PP y las $\mathrm{PD}$ en los contextos en los que se despliega el rol dual, facilitando la posibilidad de su manipulación por parte de los individuos, particularmente de aquellos como los antropólogos que se orientan por la ética disciplinaria derivada del análisis del rol asumiendo que tales desempeños contribuyen al logro de las metas sociales involucradas en los contextos. En este sentido, se asume que los roles disciplinarios y profesionales constituyen un tipo de comportamiento más y que, los antropólogos, al ser conscientes de sus propios límites, pueden contribuir a un desenlace más nítido de la interacción o transacción.

\section{Vinculación entre antropología y socie- dad a través de demandas profesionales}

El posicionamiento inicial en esta temática emerge desde una vorágine de ideas, imágenes, propósitos, expectativas, interrogantes, posibilidades e imposibilidades que sólo puede detenerse mediante un ejercicio de sistematización e interpretación del quehacer profesional y disciplinario con el propósito de restablecer diálogos con distintos actores y en distintos niveles o dimensiones de la realidad. La pregunta fundante apunta a problematizar el modo a través del cual una disciplina de cerca de ciento cincuenta (150) años puede explicitarse y hacerse presente en una perspectiva de continuidad, que establece fronteras con otras ciencias sociales y prácticas socioculturales, buscando la mejor forma de actualizarse en el presente para responder a los problemas sociales que plantea la sociedad o contexto en el cual nos desenvolvemos como antropólogos, en los que se incluye también el problema de la formación. Dicho de otro modo, el interés mayor está en encontrar un lenguaje comunicativo que permita distintos diálogos y que sea capaz, al mismo tiempo, de darse cuenta de cuándo estos diálogos no son posibles, sin que por ello deba detenerse el propósito inspirador del quehacer disciplinario y profesional.

Los fundamentos de esta perspectiva arrancan desde dos corrientes históricas: 1) la corriente de la historia larga de la antropología, respecto de la cual hemos heredado un patrimonio de modelos y PD en el marco de los modelos y las teorías científicas, que les hablan a la sociedad desde la lejanía; y 2) la corriente de la historia corta en la cual hemos sido protagonistas. En esta interrelación entre estas dos historias hemos advertido el papel de la socialización asociada a la enseñanza misma de la antropología que le ha otorgado un determinado peso a la posibilidad de transformarnos en agentes relativamente autónomos como para diseñar, ejecutar y evaluar quehaceres profesionales y disciplinarios en constante imbricación y diálogo con actores tales como: sectores administrativos e institucionales, pares cercanos y lejanos, otros estudiosos (nacionales e internacionales), estudiantes en distintos procesos de formación y los diferentes actores de la sociedad regional y nacional.

Haciendo una breve recapitulación de la historia corta, podríamos decir que el equipo que representamos ha evolucionado desde un conocimiento etnográfico - antropológico delimitado a una distinción de tipos de conocimiento y su respectiva problematización, hacia una definición teórico-metodológica de ámbitos del quehacer, concibiendo éste como "disciplinario" y diferenciándolo del "profesional". Esta última distinción puede tener un carácter descriptivo y, en ese caso, en respuesta a la tradición nomológica de las ciencias sociales, no representaría una dificultad mayor, antes bien, es una exigencia de la contemporaneidad. La complejidad inherente a esta distinción, sin embargo, subyace a su praxis, dado que los antropólogos que asumen esta perspectiva deben asumir una relación que había 
sido negada en la tradición antropológica como estrategia de crecimiento del corpus científico, específicamente, la antinomia entre antropología y sociedad (Boas, 1895, Cit. en Bohannan y Glazer, 1993). Desde luego, es imposible soslayar la pregunta acerca de si este crecimiento pueda diluirse si cambiamos el objeto y el acercamiento tradicional o convencional moviéndolo hacia las dinámicas de la sociedad y, particularmente, a las relaciones entre el quehacer disciplinario - profesional en ésta. Frente a tal cuestión, una primera respuesta deriva del aprendizaje de que todo estatus de realidad depende de su definición y, por otra parte, de que si dicha definición no crea el contexto en el cual el proceso de construcción de conocimiento tiene sentido, es imposible poder evaluar si el tipo y calidad de los problemas y de eventuales soluciones se objetiven. En otras palabras, desde luego, el concepto de crecimiento de la disciplina interviene aquí, así como la posibilidad de que el conocimiento sea coherente con las definiciones o re - definiciones que se hayan planteado para otorgarle sentido.

En consideración a lo anterior ya se está advirtiendo que la historia corta está enmarcada en una re - definición del objeto del quehacer disciplinario, lo que exige, a su vez, la formulación apropiada de los marcos teórico - epistemológicos que podrían otorgarle coherencia, aunque el sentido intuitivo -del cual no queremos desprendernos ni creemos que haya que hacerlo- ya se lo haya dado, si bien la formalización, de igual modo, se conciba como necesaria.

Al momento actual reconocemos dos fases en este proceso de redefinición del objeto. En la primera, definimos categorías conceptuales que, en calidad de "tablas de deslizamiento", nos permitieron incursionar en la sociedad, asociando los problemas sociales sentidos por la gente a tales categorías, de modo que nos permitieran el acceso directo al campo disciplinario, generando a través de ellas, por tanto, una necesaria articulación entre los desempeños disciplinario y profesional. Estas categorías fueron:

- Relaciones interétnicas e interculturales

- Desarrollo social y cultural

- Salud comunitaria, incluyendo salud mental

- Marginalidad urbana

- Derechos humanos y sociedades

- Interdisciplina, ${ }^{7}$

Aunque estas categorías están aún vigentes, dado que generaron un quehacer amplio y diverso, al mismo tiempo que con posibilidades de explicarse con relación a las características socioculturales y sociopolíticas, pronto advertimos que el quehacer disciplinario y profesional iba sobrepasando cada una de estas categorías. Así, el tema de las relaciones interétnicas e interculturales en relación con el del desarrollo social y cultural aparecían fundiéndose en uno solo y derivando hacia productos de carácter metodológico, simultáneamente con los de carácter socio-explicativos. En salud comunitaria se trabajó mayormente en el campo marginal urbano, por lo tanto, el tema de salud mapuche debió asociarse con el de relaciones interétnicas e interculturales; etc.

Hacia la primera década del siglo XXI advertimos que, desde el contenido etnográfico y analítico de la experiencia de cinco años, emerge la posibilidad de una relación distinta con la sociedad, de igual modo inspirada en la fusión alternada de las dimensiones profesionales y disciplinarias. Esta nueva relación la graficamos en el cuadro 2:

De un modo quizá más denso que en el Cuadro Número 1, el antropólogo se ve enfrentado aquí no sólo a nociones y conceptualizaciones de la sociedad, sino a conjuntos de representaciones y concepciones profundas acerca de las relaciones sociales y culturales y, particularmente, de las identidades y auto - identidades adscritas y asumidas. Se enfrenta, así, a controversias establecidas y en reformulación, con posiciones y estructuras sociales de un orden mucho más determinante en cuyos contextos debe llevar a cabo el desempeño de sus roles profesionales y disciplinarios.

En esta oportunidad ilustraremos el desempeño de estos roles en dos situaciones distintas: una con relación a la línea de la marginalidad que ha cumplido la antropología hasta el momento y otra relativa a las relaciones interétnicas. Más allá de estos ejemplos, reordenaremos el material en un plano conceptual y metodológico de segundo orden para situar en él, de nuevo, el nivel más abstracto del desempeño del rol dual.

En ambos casos, la experiencia denota un tránsito, que asumimos debe ser intencional, entre el desdén o indiferencia a la participación de la perspectiva antropológica, a una especie de acoso planteado desde sectores de la sociedad subsumidos en la trama de su complejidad "orgánica" (funcional) y a la posibilidad de una liberación interpretativa en consonancia con las cosmovisiones involucradas -particularmente la mapunche.

\section{Rol disciplinario y profesional en el cam- po de la marginalidad}

En un período de cinco años (1998 - 2003) se ha podido llevar a cabo un camino que se inicia desde el involucramiento en un problema social -específicamente en torno a las personas vaga-

\footnotetext{
7 La descripción del quehacer que estas categorias generaron se presentó de modo analitico en una matriz que incluía la dimensión disciplinaria y profesional, an Durán (2002).
} 
Cuadro 2. Vinculación entre antropología y sociedad a través de demandas profesionales. Lectura crítica y constructiva.

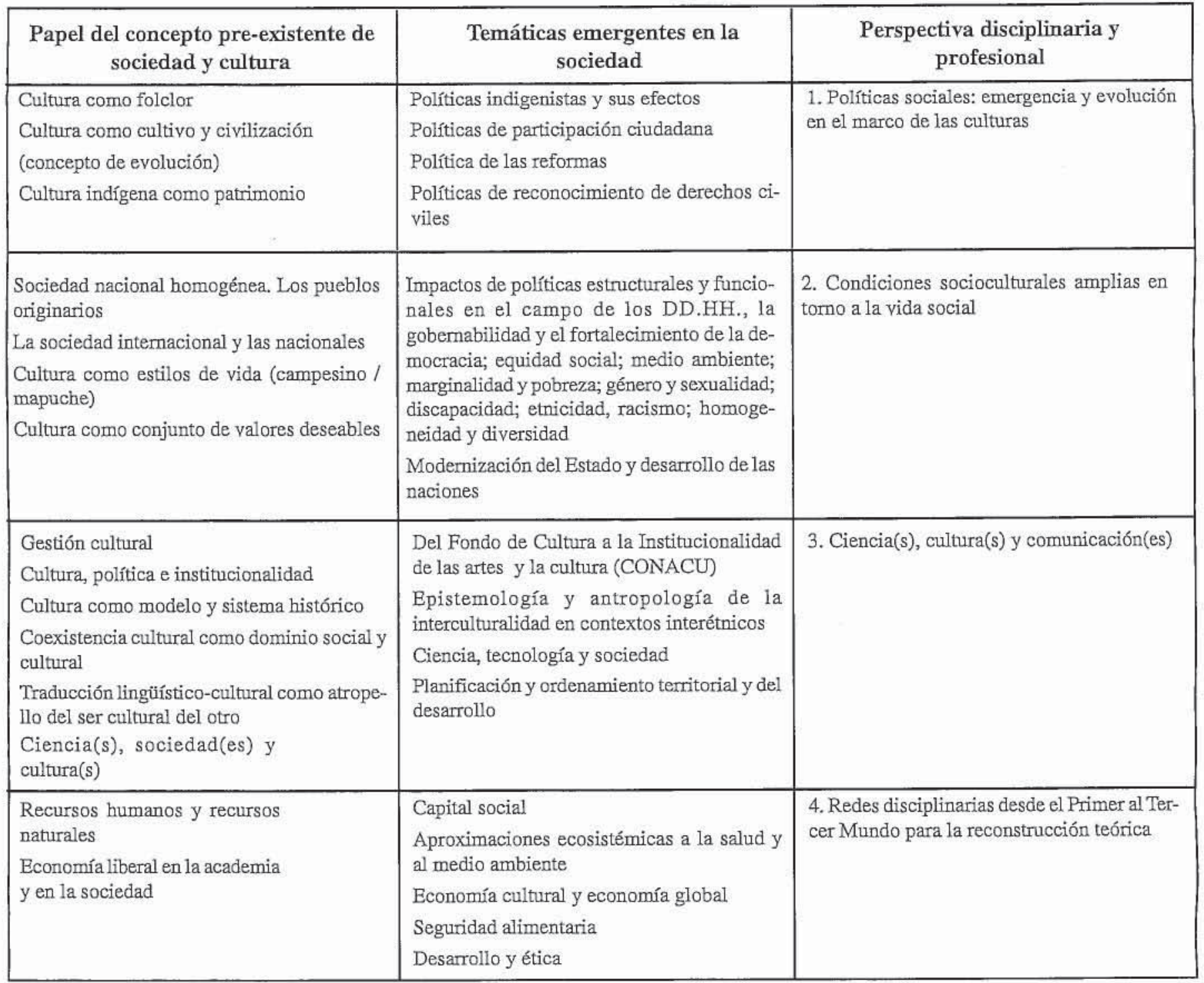

bundas de la zona urbana de la capital regional (Berho, 1998) y que avanza hacia el entendimiento de su naturaleza, en este caso marginal, moral y epistémica (Berho, 2000). En este proceso, se ha estimulado la re-codificación del mismo problema por parte de la sociedad -el que hoy día se entiende como "abandono" y/o auto-marginación-, incluyendo formas de diálogo entre actores sociales interesados en la problemática; así como por parte de la propia antropología -que, en la actualidad, 10 define a la luz de la categoría de personas sin hogar-. Cabe señalar aquí el nivel de formalización que en el plano social el involucramiento inicial ha desencadenado, traducido en un acuerdo colaborativo fundado en las diferencias socioculturales de los participantes, con miras a un tratamiento integrativo y relacional. Por otra parte, se ha ampliado la perspectiva antropológica con la filosófico - epistemológica y ética, sin aban- donar el abordaje en los contextos institucionalizados pertinentes, particularmente en servicios públicos y privados, así como en los "territorios existenciales" en que se desenvuelven habitualmente los sujetos. Particularmente en los primeros escenarios, el quehacer profesional ha consistido en la visibilización de la complejidad del problema, en la visualización de una red de apoyo y su consolidación institucional, incluyendo etapas de capacitación y en la enseñanza formalizada. En lo disciplinario, en tanto, se ha llevado a cabo una investigación disciplinaria de carácter etnográfico $(1998$ - 2002) y en el presente interdisciplinaria (2003), con lo cual el corpus cognoscitivo ha logrado entrar a la red de conocimiento disponible e institucionalmente legitimado. ${ }^{8}$ 
La enseñanza derivada de esta experiencia apunta a la configuración de una estructura disciplinaria y profesional que respeta el posicionamiento personal del antropólogo y, al mismo tiempo, lo obliga a tener que actuar, desde esta base personalizada, en los códigos culturales propios de la sociedad en la que se desempeña y desde la cual se constituyen los contextos simbólico - significativos en los que se desenvuelve el comportamiento cotidiano, así como respecto de los códigos propios del conocimiento formal que, a su vez, se asumen también como códigos culturales en los contextos formalizados del conocimiento. ${ }^{9}$

Más allá de esta enunciación de la enseñanza, interesa dejar en claro que el tiempo cronológico ha debido vivirse sobre la base de serios riesgos en la comunicación y en la perspectiva del desempeño mismo, así como también de oportunidades de proyección del desempeño. Uno de los riesgos vividos en este campo -y en latencia hasta el día de hoy-, es que en el ámbito del desempeño profesional, la etnografía contemporánea en tanto herramienta validante principal de la antropología, produjo respuestas sensibles en el "organismo" social, particularmente de parte de los actores privados involucrados en el tratamiento del problema de las personas sin hogar; estos actores, desde sus marcos ético-religiosos y en relación a otros similares, generaron una oposición entre conocimiento y verdad asumida que no fue ni ha sido fácil de superar, particularmente en la forma adoptada por el voluntariado histórico de base religiosa.

Lo anterior quiere decir que la sociedad demuestra estar activa respecto de la problematización social, particularmente cuando esta problematización no proviene de sus pares y crea en ella espacios de incertidumbre derivados del abordaje lingüísticocultural del problema así como del grado de cercanía social con respecto al mismo.

En un sentido opuesto, se encontró que otros actores sociales, especialmente los que detentan el poder centralizado, han tendido a optimizar socialmente su labor incorporando el aporte especializado que puede proporcionar la antropología, por supuesto sin abandonar, sino más bien reforzando su rol hegemónico.

En síntesis, todo lo anterior permite visualizar que los riesgos principales del rol del antropólogo en la sociedad van desde la funcionalización voluntaria, involuntaria o inducida, a niveles relativos de desplazamiento o control jurisdiccional.

\section{Rol disciplinario y profesional en el cam- po de las relaciones interétnicas}

En este campo, y en el lapso de una década, se ha mostrado que el camino ha sido similarmente azaroso y complejo. Los imperativos han sido entender que el tipo de antropología que se practica y, por tanto, el desempeño profesional, están unidos estrechamente al nivel de la consciencia que el antropólogo logra respecto de su rol en una situación que supone la coexistencia de códigos culturales no sólo distintos sino diversos en el contexto de una historia de disputas de territorios e identidades. La paradoja, en este caso, ha sido que la antropología, ya ha trabajado disciplinariamente el problema técnico concerniente a este campo propiamente tal, es decir, la inconmensurabilidad de los lenguajes (Winch, 1996) y el problema de las racionalidades (Durán et al, 2000), no obstante lo cual ha cometido los mayores errores, sometiendo a la disciplina al riesgo de su rechazo en la sociedad respecto del comportamiento profesional.

En esta perspectiva, la antropología desempeñada ha logrado liberarse del indigenismo hacia la construcción de relaciones dia-lógicas negociadas de intercambios inter-culturales en el campo social y en el cognoscitivo con diversos sectores del pueblo mapuche,${ }^{10}$ traspasando este conocimiento a los sectores de la sociedad regional que lo han solicitado. Ha debido asumir, no obstante, los riesgos que la sociedad regional le ha impuesto en la medida en que no ha sabido comprender la posibilidad de este tipo de relación; por otra parte, no todos los sectores indígenas han levantado la vigencia del "castigo" que, en este caso, el "organismo" le ha impuesto al antropólogo inmerso aún en viejos paradigmas. Al respecto, la investigación orientada a la elicitación de modelos endógenos de desarrollo, ha demostrado no ser susceptible de ser aceptada ni institucionalizada en un tiempo cercano en el marco de la sociedad nacional. ${ }^{11} \mathrm{Al}$ mismo tiempo, el conocimiento antropológico legitimante del conocimiento cultural, mapuche en este caso, tampoco ha sido aceptado por algunos sectores del movimiento indígena, en tanto sí está cobrando cada vez mayor relevancia en el ámbito de las redes internacionales. ${ }^{12}$

En síntesis, en términos formales y de contenido, se puede demostrar que la AAC supone moverse a lo menos en tres planos:

\footnotetext{
9 En particular, véase el texto de Berho, M (2001), "Personas sin hogar en Temuco. Enfoque antropológico sociocultural aplicado". II Jornadas Académicas de la Escuela de Antropología, UCT, disponible en www.portavozantropologico.cl.

10 El resultado más notable al respecto y que trazó la senda de una antropología dialógica de base experimental a nivel regional y nacional, se puede advertir en el libro de Durán et al (1997), Conocimientos y vivencias de dos familias wenteche sobre medicina mapuche. Centros Estudios Socio Culturales, UCT, LOM.

11 Nos referimos al "Plan de Desarrollo Endógeno del Ayjarewe de Xuf-Xuf. Kümeletwam", 2001-2002, GES - UCT, Organización Ayjarewe de Xuf-Xuf, MIDEPLAN; y al texto recientemente preparado "Modelos de desarrollo endógeno" (CES - UCT, 2003).

12 El movimiento mapuche regional que hoy dia lidera el "Nuevo trato" con el gobiemo y que solicitó al CES el tratamiento del campo de la salud, no logró apoyo por parte de ciertos sectores por el hecho de que este trabajo fuera elaborado por antropólogos.
} 
1) el plano del cambio de consciencia del propio antropólogo en lo que respecta al corpus de conocimiento que construye, pudiendo acceder al pensamiento antropológico;

2) el plano de las PP, las que deben insertarse como otras prácticas dentro de las tantas que la sociedad contemporánea ofrece y valida, es decir, haciendo coherencia con ellas; y

3) el plano propiamente disciplinario que lo compromete a la validación de constructos teóricos y valóricos en relación a sus pares, diferenciándolos respecto de otros paradigmas científico-éticos en vigencia.
Al respecto, proponemos el siguiente cuadro para entender el modo como el antropólogo aplicado contemporáneo puede transitar en este último plano (3) y, desde él, hacia los anteriormente mencionados, tomando como referente analítico la existenica de contextos científicos y sociales en los diversos problemas. En este caso, hemos tomado dos de carácter general, los que son abordados, tratados y resueltos en el marco de los modelos socioculturales y científicos vigentes y transformadores -en este último caso, nos referimos a los modelos de ciencia normal (Kuhn, op. cit.) y pos-normal (Funtowicz y Ravetz, op. cit.).

\section{Cuadro 3. Tránsito del antropólogo en el contexto científico y social.}

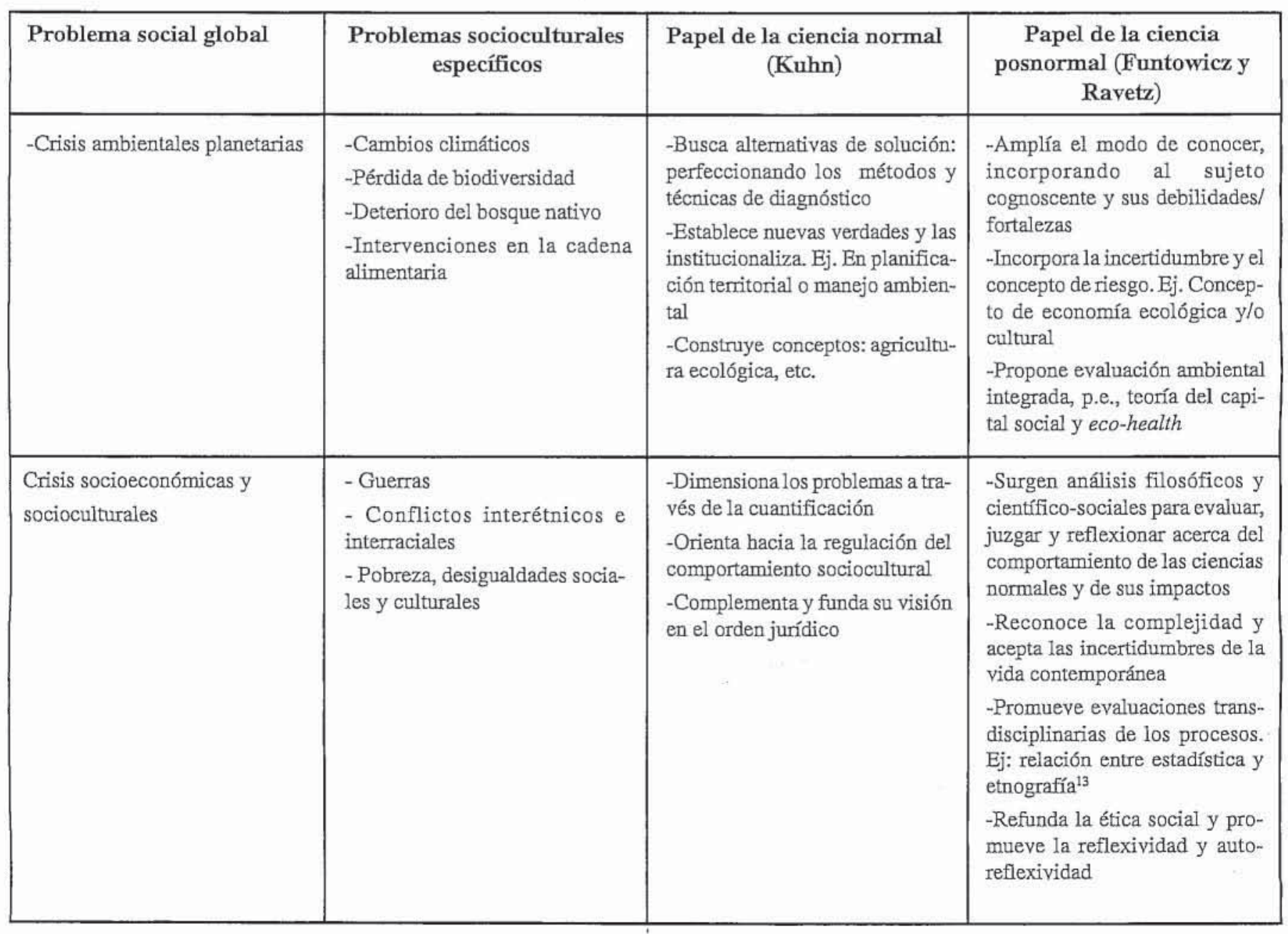




\section{Cuando la antropología se hace pedagogía}

En un nuestra experiencia profesional y disciplinaria el tránsito entre la ciencia normal y pos-normal, así como entre el rol disciplinario y el profesional, se ha vivido a través de tres principales tipos de espisodio de enseñanza - aprendizaje delimitado y sistemáticos:

a) la enseñanza de la antropología en un nivel de pre grado. ${ }^{14}$

b) la enseñanza de la antropología en un nivel de pos - grado en temáticas socioculturales y antropológicas ${ }^{15 .}$

c) la enseñanza de antropología en un contexto de divulgación científica.

a) En relación al primer tipo de enseñanza la mayor dificultad ha estado en lograr legitimidad en el aprendizaje de un modelo de antropología, tanto entre los pares como entre los aprendices, bajo la convicción de que el mayor esfuerzo debe ponerse, no tanto en la relación con otros modelos, sino más bien en sustentar su coherencia. Se ha logrado discernir, en este campo, el rol cultural, ideológico y político subyacente a las "mallas curriculares", por ejemplo, y, por ende, a la existencia o no de "comunidades científicas" de práctica antropológica, así como al rol del mismo orden que cumplen las instituciones que otorgan y administran estas carreras y los contextos institucionales y sociales amplios (Durán, 1998).

Hoy día se ha descubierto con mayor acuciosidad la compleja red de conceptualizaciones de antropología con las que los sujetos ingresan y deben enfrentarse si se están desempeñando profesionalmente (ver Cuadro $\mathrm{N}^{\circ} 1$ ) ${ }^{16}$ así como los aportes reales e ideales de los sectores responsables en el contexto social y formativo. Ello supone aceptar la diversidad de conceptualizaciones vigentes de antropología por parte de los antropólogos, al mismo tiempo que vislumbrar la factibilidad de un consenso operacional que sustente la base teórico metodológica de los planes curriculares. ${ }^{17}$

En este campo, los mayores riesgos consisten en el impacto individual y medianamente colectivizado relativo a la incorporación de consensos por parte de los distintos actores, asumiendo que el "organismo" exige tiempos y espacios simbólicos distintos y reacciones psico - orgánicas diversas. ${ }^{18}$ Paradojalmente, los principales riesgos y posibilidades en los últimos tres años han estado asociados a las nuevas normativas institucionales y, al mismo tiempo, a las posibilidades de los antropólogos de lograr los consensos operacionales. En efecto, la universidad otorga autonomía relativa a las escuelas para administrar los planos "profesionales" y "disciplinarios" en la formación. Paralelamente, estos planos se han potenciado para ampliar el ámbito de la teoría de la antropología interactiva como forma de concebir y hacer AAC.

En la experiencia analítica de las PP al interior de la Escuela, se revela que las principales limitaciones han provenido no de la sociedad que recibe $y / 0$ demanda los servicios profesionales sino más bien de la dificultad de que el sector estudiantil resuelva la pugna de incompatibilidad entre el rol social y el antropológico. En otras palabras, de un problema que concierne al comportamiento individual en relación a las oportunidades que ofrece el contexto para liberarse y/o mantener nociones prevalecientes, en este caso particular, las nociones de antropología atadas a los modelos clásicos y modernos de raigambre emancipadora y/o reivindicativa.

b) En el campo de los programas de pos-grado, el mayor desafío de la antropología local ha estado en la contextualización del conocimiento nomotético respecto del abordaje de los problemas locales, particularmente en sociedades multiétnicas y multiculturales, al punto de fundar la idea de que un conocimiento de orientación científica es tal si es capaz de transitar entre el nomos y los logos particulares.

En lo específico, dentro de este campo la antropología ha debido desenvolverse de modo crítico, analítico y persuasivo no sólo entre el logos particular dominado y el dominante sino vislumbrar el modo a través del cual las relaciones de dominación puedan redefinirse mediante la explicitación de modelos diversos de construcción de conocimientos.

c) A través de cuatro experiencias de divulgación científica, se ha logrado vislumbrar que cuando la antropología interactiva como AAC ha alcanzado condiciones mínimas de formalización de la PP y la PD, los conocimientos socioculturales y propiamente antropológicos logran reposicionarse en los individuos. Sólo a modo de ilustración, nos referiremos a un caso -sustentado en dos ejemplos durante el presente año- que muestra el impacto de una docencia inspirada en una intencionalidad antropológica como la descrita. La docencia se caracterizó del siguiente modo: ${ }^{19}$

- Explicitación y desentrañamiento de la base epistemológico-social de los individuos participantes respecto del tema.

14 Escuela de Antropología de la Universidad Católica de Temuco, Chile.

15 Magister en Educación Intercultural Bilingüe en Contexto Mapunche, UCT 2002 - 2003; Magister Intemaclonal en Agricultura y Desarrollo Sustentable, Centro de Desarrollo Sustentable, UCT, $2000-2001$.

16 Ver Proyecto de Innovación Docente de la Escuela de Antropologla de la UCT, 2002 - 2003.

17 Ver Propuesta de Plan Curricular 2004, de la Escuela de Antropologia de la UCT, tendiente al proceso de acreditaclón de enseñanza superior.

18 Al momento de escribir el original de este texto, la Escuela de Antropologia de la UCT estaba atravesada por una huelga de hambre de los estudiantes en pro del cambio estructural de las medidas disciplinarias de la instituclón en el ámbito de la participación estudiantil y, particularmente, en el marco de las "tomas" ilegales del recinto institucional.

19 Curso "Desarrollo y pueblo mapuche": participantes ingenieros del centro - sur de Chile, UCT, primer Semestre, 2003. 
- Explicitación de los marcos referenciales transdisciplinarios, específicamente los modelos de ciencia como dispositivos de conocimiento.

- Explicitación técnica de los temas identificados como deseables de conocer, particularmente los culturales.

-Incorporación de antecedentes socio-históricos y temáticos (desarrollo endógeno y salud como modelo cultural).

-Generación de espacios de discernimiento y crítica a la epistemología social fundante, particularmente centrada en la percepción, el estereotipo y el conocimiento de sentido común.

A modo de síntesis, esta experiencia de divulgación antropológica podría considerarse un modelo cultural persuasivo, intencionado y casuístico, de impacto sociocultural latente.

\section{Recapitulación}

En términos generales, diremos que el CSM de la sociedad latinoamericana compleja que, en lo regional, centra su atención en el desarrollo económico desde la explotación de sus recursos naturales, particularmente a partir de su inclusión en redes de intercambio globalizado que los transforma y que, al mismo tiempo, se precave del "conflicto social" por el impacto problemático que éste representa respecto de tal desarrollo, desde luego plantea un desafío y una perspectiva compleja a la AAC. ${ }^{20}$
Este desafío está ligado, a su vez, a las reflexiones de los antropólogos respecto de las posibilidades que los modelos en ejercicio han proporcionado en el ámbito de su quehacer. Una antropología social de apoyo (Colombres, 1997) que se autoclausura al término del problema social se situará en nuestra perspectiva al nivel del voluntariado social; una antropología funcionalista comprometida con el reduccionismo jurídico, económico y político de las instituciones sociales que se piensan para hacer prevalecer y proyectar en el tiempo el poder de las políticas sociales, necesariamente terminará por reducir la capacidad disciplinaria de los antropólogos que aún la practican. Por último, una antropología que se escuda en las corrientes pos-modernistas y en el poder discursivo alternativo del lenguaje dejará al antropólogo circunscrito al ámbito académico estético y/o intelectual, como si la inyección de ideas a los sistemas fuera suficiente para la promoción del cambio sociocultural.

Por otra parte, proponer una antropología que asuma un camino desde los entes que siempre están o han estado, como el individuo - persona, la sociedad, sus instituciones y las condiciones socioculturales amplias en que la gente proyecta, sueña y vive; y las posibilidades que las mismas personas tienen de trascender culturalmente los tiempos del "organismo" social representa, desde luego, una dificultad enorme. No obstante, nuestra experiencia muestra que es posible no sólo practicar este tipo de antropología, sino representarla a través de las ideas disponibles. En esta oportunidad recurriremos al diagrama siguiente.

El diagrama presentado quiere decirnos que la disciplina antropológica, en su esfuerzo de hacerse profesión, termina siendo un comportamiento sociocultural evaluable y evaluador de

Figura 1. Dualidad del rol antropológico en la ciencia y la sociedad.

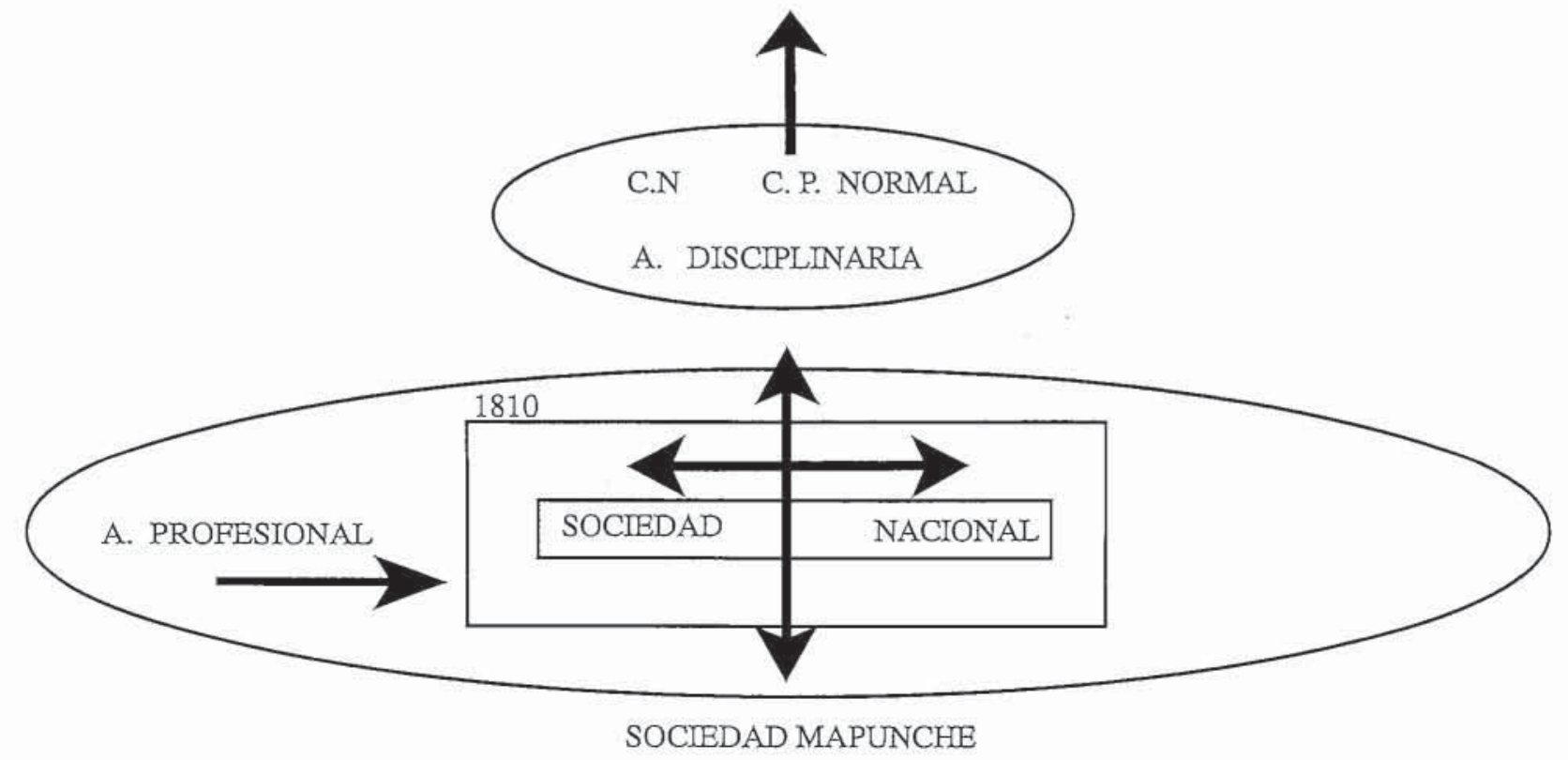


otros, tras la búsqueda de puntos de encuentro, en que el desencuentro no es la excepción. El antropólogo debe ser la persona que asuma prepararse constantemente para, desde el equilibrio multifacético y precario del "organismo" social, pueda estar con los otros considerando la posición que estos adoptan a partir del impacto que su propia conducta provoca en ellos. La refrendación de la última afirmación no proviene sino de las últimas teorías pos-normales ya en circulación (Funtowicz y Ravetz, Op. cit.; Tuhiwai, 1999).

En lo específico, el ejercicio desarrollado, visto como una especie de laboratorio analítico en el cual nuestras prácticas se insertan, nos permite responder de un modo sintético a las preguntas inicialmente formuladas y desencadenantes de la reflexión.

1) Ningún contexto, ni siquiera el multicultural, impide la construcción de conocimiento profesional y disciplinario de carácter antropológico. La experiencia analizada demuestra que el manejo transversalizado de las VC de diferenciación de los roles no sólo facilita la construcción de un conocimiento diferenciado como es deseable, sino que -lo más importante- facilita la acción. La lección obtenida es que es necesario responder a las demandas que la sociedad plantea ojalá en términos similares a como ésta las expresa, pero al mismo tiempo es necesario obtener una respuesta antropológica, en cierto modo a-social, de modo de superar el límite en el cual las explicaciones sociales se auto-contienen $y / o$ se confrontan, como aporte a una manera distinta de visualizar la problemática.

2) La construcción de conocimientos duales constituye la mejor oferta a la sociedad de parte del antropólogo. Ello se ha podido ver especialmente en relación con problemáticas sociales extremas como la marginalidad social y las relaciones interétnicas desequilibradas en las que la sociedad, por un lado, se niega, por razones ideológicas, a trascender los modelos aprendidos, pero al mismo tiempo es más vulnerable a permitir la generación y/o conocimiento de visiones distintas a la suya. En este sentido, la relación del conocimiento antropológico con el conocimiento social en tópicos de interés antropológico es posible y puede direccionarse, aunque el impacto sea variado y disímil. Podría decirse entonces que el conocimiento antropológico al que aspiramos como cultivadores de una $A A C$ constituiría una segunda lectura del conocimiento social orientado desde modelos culturales más amplios e integrativos; esta segunda lectura pareciera estar constituyendo en los contextos latinoamericanos un dispositivo potencial, variablemente usado o aprovechado, pero más sensible; en contraste a como ocurre en Europa donde no se desconoce su presencia, pero tampoco se sensibiliza su uso controversial.

3) Finalmente, las posibilidades de reorientar las prácticas antropológicas a través de la enseñanza parecieran estar asociadas al proceso de formalización del modelo, particularmente del que hemos estado planteando hasta aquí-AAC- que, necesariamente, debe buscar los enlaces para encontrar significatividad respecto de otros modelos de antropología y de otras disciplinas. En otras palabras, el modelo de AAC que proponemos sobre la base de la dualidad -que se asume necesariamente como un modelo de antropología interactiva-, posibilita la diferenciación respecto de otros y, por tanto, no se auto-clausura ni es tampoco excluyente.

\section{Bibliografía}

AZCONA, J. (1999), Teoría y práctica de la antropología social, Universidad del país Vasco, Bilbao.

BERHO, M. (1998), "Esbozo para una etnografía del vagabundo". CUHSO 4(1):38-43

BERHO, M. (2000), "Una carrera hacia los bordes de la sociedad". CUHSO 5(1):45- 56.

BOAS, F. ([1895] 1993), 'Las limitaciones del método comparativo en antropología", en Paul Bohannan y Mark Glazer (Comps.), Antropología. Lecturas, Mac Graw Hill, Madrid.

BOURDIEU, P. (2000), El oficio del sociólogo, Siglo XXI, Madrid.

CABRERA, P. (1998), Huéspedes del aire, Pontificia Universidad de Comillas, Madrid.

COLOMBRES, A. (1997), "Antropología social de apoyo", en Antropología Aplicada, U. P.S., Quito.

DURÁN, T., QUIDEL, J. \& HAUENSTEIN, E. (1997), Conocimientos y vivencias de dos familias wenteche sobre medicina mapuche. Mapuche lawentüwün epu reyñma wenteche ñi kimün mew, Centro de Estudios Socioculturales, Universidad Católica de Temuco, LOM, Santiago.

DURÁN, T. (1998), "Sustentación de un curriculum para la formación en antropología. Notas desde una experiencia local", en Actas III Congreso Chileno de Antropología, Universidad Católica de Temuco, Temuco.

DURÁN, T. (2000), "El papel del conocimiento en las relaciones interétnicas y el desarrollo", en Pueblo mapuche, desarrollo y autogestión, Universidad de La Frontera, Escaparate, Santiago.

DURÁN, T., E. PARADA \& N.CARRASCO (2000), Acercamientos metodológicos hacia pueblos indígenas. Una experiencia reflexionada desde La Araucanía, Centro de Estudios Socioculturales, Universidad Católica de Temuco, LOM, Santiago.

DURÁN, T. (2002), "Antropología interactiva. Un estilo de antropología aplicada en la IX de La Araucanía, Chile", en CUHSO, Volumen 6(1):23 - 57 . 
DURÁN, T., MONCADA, J. \& MORA, H. (2002), "El papel de la estadística y la etnografía en la formalización del conocimiento científico social". Revista de la Escuela de Antropología, Volumen VII, Noviembre, Universidad Nacional de Rosario, Facultad de Artes y Humanidades, Argentina, pp. 49 - 61.

FUNTOWICZ \& RAVETZ (2000), La ciencia posnormal. Ciencia con la gente, Icaria Antrazyt, Barcelona.

GARCÍA CANCLINI, N. (2002), Latinoamericanos buscando lugar en este siglo, EUDEBA, Buenos Aires.

GEERTZ, C. (1996), Tras los hechos. Cuatro décadas, dos países y un antropólogo, Paidós, Barcelona.

GEERTZ, C. (2000), Reflexiones antropológicas de temas filosóficos, Paidós, Barcelona.

GIDDENS, A. (1997), Las nuevas reglas del método sociológico, Amorrortu, Buenos Aires.

GIDDENS, A. (2000), Modernidad e identidad del yo, Península, Barcelona.

GLASERSFELD, E. (1998), "Despedida de la objetividad", en Paul Watzlawick y Peter Krieg (Comps.), El ojo del observador. Contribuciones al constructivismo, Gedisa, Barcelona.

HAMMERSLEY \& ATKINSON, P. (1994), Etnografía, Paidós, Barcelona.

HARRIS, M. (1993), Desarrollo de la teoría antropológica, Siglo XXI, México.

HOLY, L. \& STUCHLIK, M. (1987), Actions, norms and representations. Foundations of anthropological inquiry, Routledge, U.K.

HOLY, L. \& STUCHLIK, M. (1988), Folk models, Routledge, U.K.

KLIKSBERG, B. (2000), La lucha contra la pobreza en América Latina, Fondo de Cultura Económica, Banco Interamericano de Desarrollo, Congreso Judío Latinoamericano, Buenos Aires.

KLUCKHOHN, C. (1949), Antropología, Fondo de Cultura Económica, México.

KUHN, T. (1971), La estructura de las revoluciones científicas, Fondo de Cultura Económica, México.

LUQUE, E. (1999), Conocimiento antropológico, Siglo XXI, Madrid.

MATURANA, H. (1998), "La ciencia y la vida cotidiana: Ia ontología de las explicaciones científicas", en Paul Watzlawick y Peter Krieg (Comps.), El ojo del observador. Contribuciones al constructivismo, Gedisa, Barcelona.

MORIN, E. (1998), Ciencia con consciencia, Anthropos, Barcelona.

MARZAL, M. (1994), Historia de la antropología. Historia del indigenismo en México y Perú, Pontificia Universidad Católica de Perú, Lima.

REYNOSO, C. (1998), Corrientes teóricas en antropología, Biblos, Buenos Aires.

RITZER, G. (1996), Teoría sociológica contemporánea, Mac Graw Hill, Barcelona.

ROMANI, O. (1998), "Antropología de la marginación. Una crítica a la incertidumbre”, en Prat J., Martínez, A. (Eds), Ensayos de antropología cultural, Ariel, Barcelona.

ROSALDO, R. (1999), Cultura y verdad, Abya - Yala, Quito.

SAMANIEGO, M. \& T. DURÁN (2003), "La problemática de construcción del conocimiento en ciencias sociales en $\mathrm{La}$ Araucanía, Chile. Propuesta interdisciplinaria de trabajo desde la antropología y la epistemología", en Revista Líder 8(8) :105115.

SPIRE, P. (2000), El pensamiento de Prigoggine. La belleza del caos, Andrés Bello, Santiago.

STUCHLIK, M. (1976), Life on a half share. Mechanism of social recruitment among the mapuche of southern Chile, Billing \& Sons, U. K.

TAUSSIG, M. (1995), Un gigante en convulsiones, Gedisa, Barcelona.

TUHIWAI, L. (1999), Decolonizing methodologies. Research and indigenal people, Zed Books, U.K \& New Zealand.

ULIN, R. (1990), Antropología y teoría social, Siglo XXI, México.

VIDAL, A. (1999), "Políticas legislativas en Chile. El caso de las tierras y territorios mapuche", en CUHSO, Volumen Especial, $N^{\circ} 1$, Legislación Indígena, tierras y pueblo mapuche, Centro de Estudios Socioculturales, Universidad Católica de Temuco, pp. $67-111$.

WINCH, P. (1996), Comprender una sociedad primitiva, Paidós, Barcelona.

YOUNG, A. (1990), "(Mis) applying medical anthropology in multicultural settings", en Santé, Culture, Health, Volume VII $(2-3): 197-208$. 